\title{
$J^{3}$ LETTERS
}

\section{Packaging of optical fibers using microfabricated nickel clamps}

\author{
Xuhan Dai, Xiaolin Zhao, Guifu Ding, Hong Wang, and \\ Bingchu Cai \\ Shanghai Jiaotong University, Institute of Micro and Nano \\ Science and Technology, National Key Laboratory of \\ Nano/Micro Fabrication Technology, Key Laboratory for Thin \\ Film and Microfabrication of Ministry of Education, \\ Huashang Road 1954\#, Shanghai 200030, China \\ E-mail: xhdai@sjtu.edu.cn
}

Abstract. Reports the microfabricated nickel clamps for packaging of optical fibers in photonics devices. When the fiber is inserted into the silicon $V$ groove, the microfricated clamps fix it in the $V$ groove. Compared with the traditional silicon $\mathrm{V}$ grooves, this approach only involves one additional sputtering, photolithography, and electroplating process. Two single-mode optical fibers were fixed into the silicon $\mathrm{V}$ groove by the nickel clamp; the measured insertion loss is lower than $0.1 \mathrm{~dB}$. ( ) 2008 Society of Photo-Optical Instrumentation Engineers. [DOI: 10.1117/1.2896082]

Subject terms: packaging; photonics; optical fiber; clamp.

Paper 07039LRR received May 30, 2007; revised manuscript received Nov. 13, 2007; accepted for publication Dec. 3, 2007; published online Mar. 25, 2008. This paper is a revision of a paper presented at the SPIE Conference on Passive Components and Fiber-Based Devices II, Nov. 2005, Shanghai, China. The paper presented there appears (unrefereed) in SPIE Proceedings Vol. 6019.

\section{Introduction}

High precision passive alignment technique is of great importance in reducing the packaging cost of optoelectronics devices. Currently, the anistropically etched $\mathrm{V}$ groove in a silicon wafer has been widely adopted to facilitate the packaging of optical fibers. However, it is the fiber attachment that precludes passive alignment from becoming a cost-effective technique. In most cases, the optical fiber is fixed into the $\mathrm{V}$ groove by gluing or welding. For the case of gluing, some inherent precision of the $\mathrm{V}$ groove is lost due to glue wicking or other effects. Welding is cleaner and gives more stable result than gluing, but it requires metallization of both the $\mathrm{V}$ grooves and the fibers, which is expensive.

To solve that problem, a mechanical solution was adopted that eliminated gluing or welding of the fiber. The fiber was held with micro clips that were fabricated onto the silicon substrate and integrated with the rest of the optical system. In practice, sets of clips protruding from the edges of $\mathrm{V}$ grooves were deflected by the fiber and acted as springs holding the fiber reliably in place. Clips made of doped silicon or silicon nitride have been reported in the literature. ${ }^{1,2}$ However, the fabrication of the clips involved a photovoltaic, electrochemical etch-stop technique, or chemical vapor deposition process, both of which may lead to a stress relief problem, which makes the adjustment of

$1537-1646 / 2008 / \$ 25.00$ @ 2008 SPIE
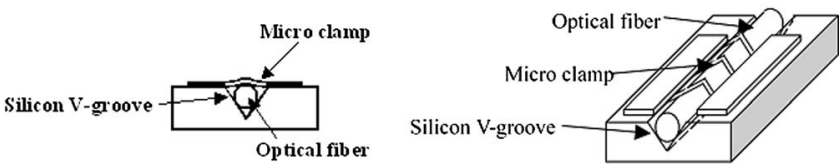

Fig. 1 The optical fiber packaged in the $\mathrm{V}$ groove via nickel clamp.

process parameters rather difficult. In addition, the doped silicon and the silicon nitride are rather brittle materials, which may not be fit for reliable packaging of optical fibers in the $\mathrm{V}$ groove.

This letter presents a unique method to solve those problems. The electroplated nickel micro clamp was fabricated above the silicon $\mathrm{V}$ groove. The fabrication process of the nickel micro clamp is described in detail. In addition, two single-mode optical fibers were fixed into the silicon V groove by the nickel clamp to verify the efficiency of the approach.

\section{Principle and Microfabrication Process of the Micro Clamp}

The principle of the micro nickel clamp is indicated in Fig. 1.The micro clamps bestride the optical fiber. As a result, the optical fiber will be fixed into the silicon $\mathrm{V}$ groove by the elastic force induced by the deformation of the micro clamp.

The fabrication process of the traditional silicon $\mathrm{V}$ groove and the micro nickel clamp is shown in Fig. 2. The typical process for fabrication of silicon $\mathrm{V}$ groove is described in the left column of Fig. 2.

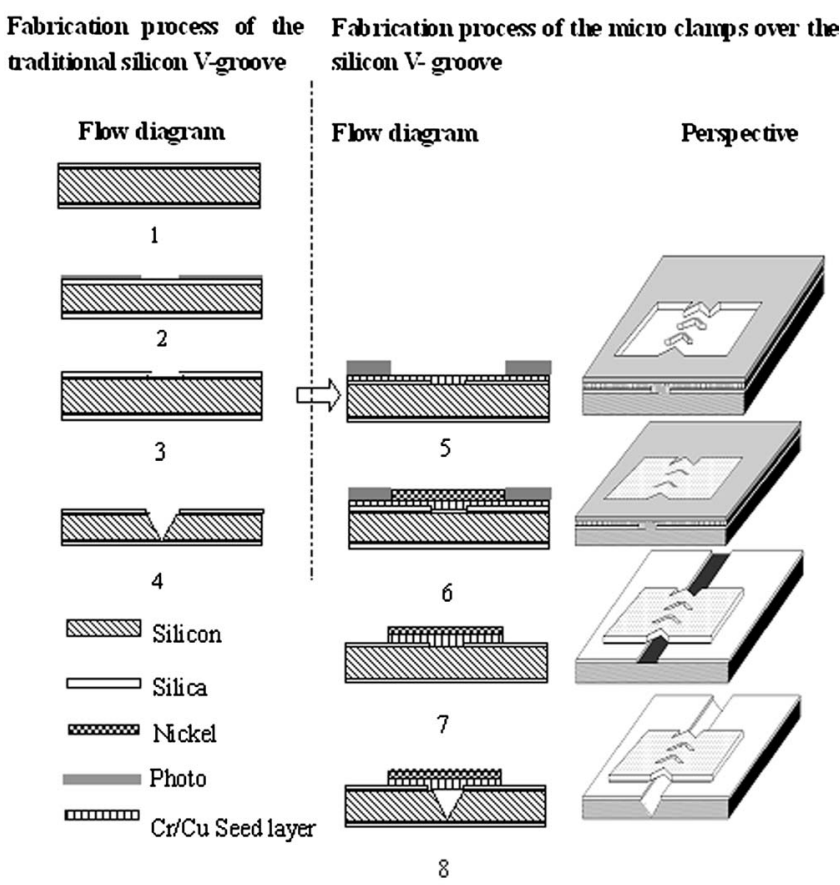

Fig. 2 Fabrication process of the traditional silicon $\mathrm{V}$ groove and the micro clamps over the silicon $\mathrm{V}$ groove. 


\section{$J^{3}$ LETTERS}

1. The 3-in $n$-type (100) silicon wafer was thermally oxidized to form $2-\mu \mathrm{m}$ silicon dioxide on both sides of the wafer.

2. The 3- $\mu \mathrm{m}$ AZ4330 photoresist (PR) layer was spuncoated onto the wafer and patterned (MA6 Karl Suss, Garching, Germany) to form the mask of the V groove.

3. Using the patterned PR as a mask, the silica layer on the front side of the wafer was pattern by reactive ion etching (RIE, NE100, Nextral Inc., Saint Ismier, France). Then the PR was stripped.

4. Finally, the silicon wafer was anisotropically etched in a closed vessel with $44 \% \mathrm{KOH}$ solution at $80 \pm 0.2^{\circ} \mathrm{C}$ to form the $\mathrm{V}$ groove on the wafer.

The fabrication process of the nickel clamp is indicated in the right column of the Fig. 2. Only one additional sputtering, photolithography, and electroplating process was inserted between steps 3 and 4 .

5. After RIE of the silica indicated in step 3, Fig. 2, a chromium (20-nm)-copper (60-nm) seed layer was sputtered (Z550 Magnetron sputtering system, Leybold-Heraeus, Hanau, Germany) onto the patterned silica layer. Then a 20- $\mu \mathrm{m}$ PR (AZ4620, AZ Electronic Materials, Tokyo, Japan) layer was spun onto the seed layer and patterned to form the mold for later electroplating.

6. A 12- $\mu \mathrm{m}$ nickel clamp was electroplated onto the seed layer. The chemical composition of the electroplating bath is indicated in Table 1 .

7. After the PR was stripped, the copper seed layer was wet-etched with a solution of ammonia and hydrogen peroxide (20:1), then the chromium seed layer was etched with a solution of $70 \% \mathrm{HClO}_{4}(42 \mathrm{ml} / \mathrm{L})$ and $\left(\mathrm{NH}_{4}\right)_{2} \mathrm{Ce}\left(\mathrm{NO}_{3}\right)_{6}(165 \mathrm{~g} / \mathrm{L})$.

8. Next, the wafer was anisotropically etched in the $44 \% \mathrm{KOH}$ solution at $80 \pm 0.2^{\circ} \mathrm{C}$ to form the $\mathrm{V}$ groove in the silicon wafer. Because the nickel could barely react with $\mathrm{KOH}$ solution, it would stay above the silicon $\mathrm{V}$ groove instead of being etched. Because the layout of the clamp includes convex corners, the silicon under the clamp would be under etched via convex corner effect. ${ }^{3}$ Finally, a smooth, straight V groove integrated with the nickel clamp was obtained. The completed clamp is shown in Fig. 3. The width and length of each arm of the clamp are 50 and $200 \mu \mathrm{m}$ separately. The thickness is $12 \mu \mathrm{m}$.

Table 1 Electroplating condition for the nickel clamp.

\begin{tabular}{lcccc}
\hline \hline \multicolumn{2}{c}{$\begin{array}{c}\text { Chemical Compositon of } \\
\text { Electroplating Bath }(\mathrm{g} / \mathrm{L})\end{array}$} & $\begin{array}{c}\text { Agitating } \\
\text { Method }\end{array}$ & $\begin{array}{c}\text { Current } \\
\text { Density } \\
\left(\mathrm{mA} / \mathrm{cm}^{2}\right)\end{array}$ & $\mathrm{pH}$ \\
\hline $\mathrm{Ni}\left(\mathrm{NH}_{2} \mathrm{SO}_{3}\right)_{2} \cdot 4 \mathrm{H} 2 \mathrm{O}$ & $(270)$ & $\begin{array}{c}\text { Air } \\
\text { bubble } \\
\text { agitating }\end{array}$ & 20 & 3.2 \\
$\mathrm{H}_{3} \mathrm{BO}_{3}$ & $(30)$ & & \\
$\mathrm{NiCl}_{2} \cdot 6 \mathrm{H}_{2} \mathrm{O}$ & $(15)$ & & \\
$\mathrm{C}_{12} \mathrm{H}_{25} \mathrm{SO}_{3} \mathrm{Na}$ & $(0.05 \sim 0.1)$ & & \\
\hline \hline
\end{tabular}

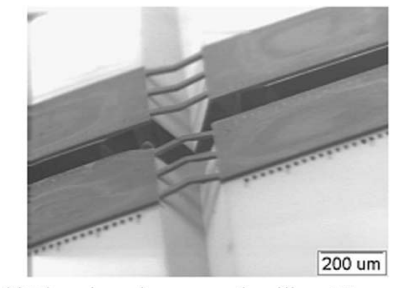

(a) The micro clamp over the silicon $\mathrm{V}$ groove

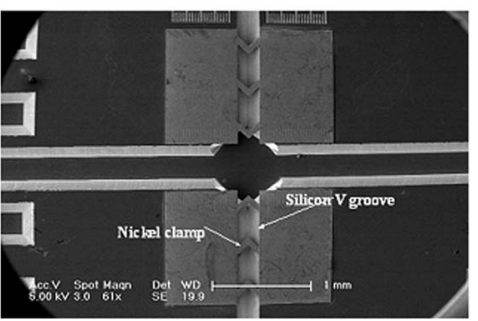

(c) The top view of the micro clamp over the silicon $V$ groove

Fig. 3 The completed nickel clamp over the silicon $\mathrm{V}$ groove.

According the processs described above, the fabrication of the nickel clamp only added one additional sputtering, photolithography, and electroplating process to the traditional silicon $\mathrm{V}$ groove. So it is fully compatible with the current technology. Compared with the process in the literature, ${ }^{1,2}$ it did not involve the expensive chemical vapor deposition equipment or complicated electrochemical etchstop process. Also, No high temperature treatment was required. So the effect of the stress relief problem was minimized. In addition, compared with the brittle doped silicon and silicon nitride clamp, ${ }^{1,2}$ the nickel approach is more robust and reliable.

\section{Fiber Inserted Into the V Groove}

To demonstrate the efficiency of the nickel clamp, two single-mode optical fibers were fixed into the $\mathrm{V}$ groove by the clamp, as indicated in Fig. 4. The packaging was carried out manually. In the figure, the size is not proportional to the real size.

1. The cleaved optical fiber was fixed by the fiber optic positioner to make its horizontal direction coincide roughly with the $\mathrm{V}$ groove. Then it was made angled (approximately $20^{\circ}$ ) down toward the $\mathrm{V}$ groove. Next, the optical fiber was moved down until it touched the sidewall of the $\mathrm{V}$ groove.

2. Because the fiber was elastic, and its horizontal direction coincided roughly with the groove, the part that touched the groove would conform to the sidewall automatically. Then the fiber was moved along the sidewall to the micro clamp at $1 \mathrm{~mm} / \mathrm{s}$ while being angled down.

3. When the fiber touched the micro clamp, it would overcome the elastic force inside the clamp and lift the micro clamp up. With the engagement of the optical fiber, the clamps bestrode the optical fiber and fixed it in the $\mathrm{V}$ groove.

4. Then another optical fiber was aligned and fixed from other side. 


\section{$J^{3}$ LETTERS}

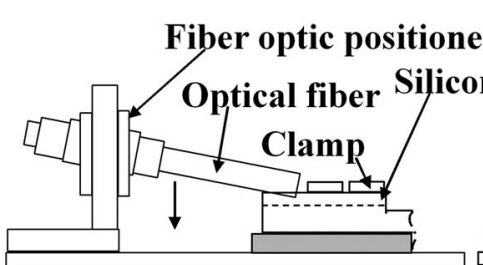

1)

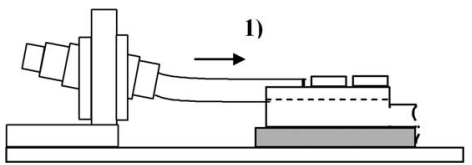

2)

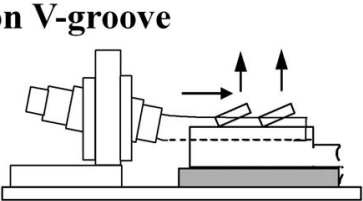

3)

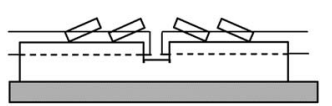

4)
Fig. 4 The new packaging process with the micromachined clamp.

After the fiber was fixed in the $\mathrm{V}$ groove, the relative position error between the two optical fibers was determined by the fabrication accuracy of the silicon $\mathrm{V}$ groove. This error could be kept under $1 \mu \mathrm{m}$ with the photolithography technology.

During this process, the tradeoff between the elastic force inside the clamp and the packaging accuracy should be considered. If the force was too small, the direction of the optical fiber might not coincide with the $\mathrm{V}$ groove, which led to a poor packaging result. If the force was too large, the packaging result might be fine, but it would be difficult for the optical fiber to lift the clamp up. The force is mainly determined by the thickness of the clamp. According to the experimental result, the optimal thickness was about $12 \mu \mathrm{m}$.

The traditional alignment and packaging process needs complex three-dimensional adjustment, which requires expensive equipment and consumes a lot of time. In contrast, with the micromachined clamp, the new packaging process only needs two fiber optic positioners. Because the clamp and the $\mathrm{V}$ groove determined the fiber direction, no complex three-dimensional adjustment was required.

After packaging, the insertion loss was measured. The wavelength for measurement was $1550 \mathrm{~nm}$. Figure 5 is the

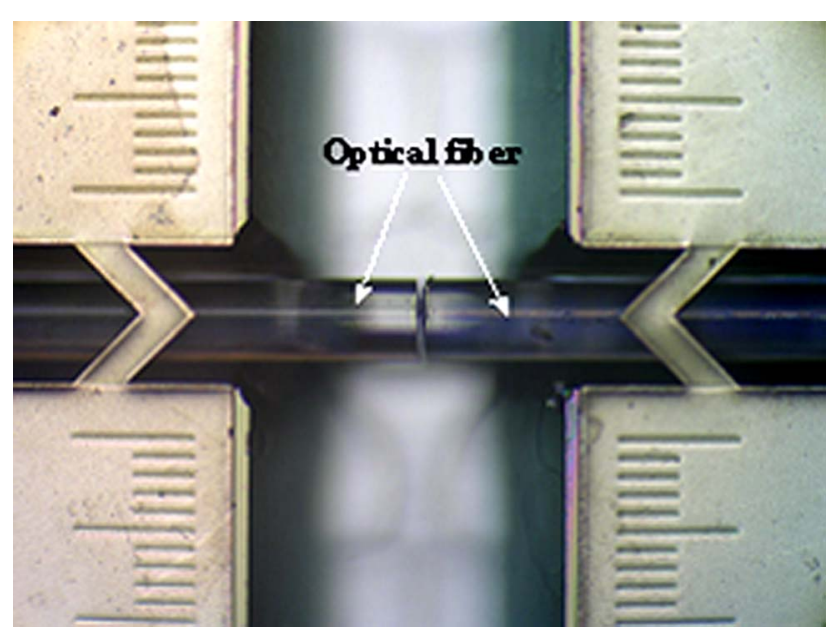

Fig. 5 Two optical fibers packaged in a silicon $\mathrm{V}$ groove with nickel clamps.

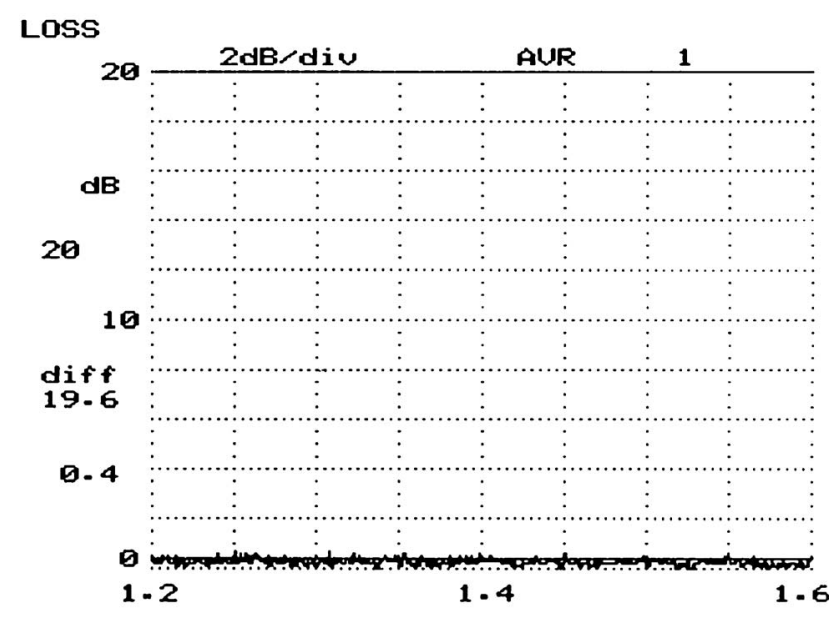

Fig. 6 The measured wavelength-dependent loss (from 1200 to $1600 \mathrm{~nm}$ ).

photograph of the two single-mode optical fibers packaged in a silicon $\mathrm{V}$ groove with nickel clamps holding them in position. The normal-cleaved fiber ends were antireflectioncoated to approximately $0.1 \%$ reflectivity to reduce FabryPerot resonance. The gap between the two ends was approximately $10 \mu \mathrm{m}$. The measured insertion loss was lower than $0.1 \mathrm{~dB}$ (98\% coupling, better than $0.5 \mu \mathrm{m}$ accuracy). In addition, the optical spectral response of the packaged device was also measured (HP71450B Optical Spectrum Analyzer, Hewlett-Packard Company, Santa Rosa, USA; Fig. 6); the wavelength-dependent loss (from 1200 to $1600 \mathrm{~nm}$ ) was less than $0.4 \mathrm{~dB}$.

\section{Summary}

A unique nickel micro clamp for packaging of optical fiber in photonic devices is presented. The fabrication process of the clamp only involves one additional sputtering, photolithography, and electroplating process. So it is fully compatible with the conventional process for fabrication of a silicon $\mathrm{V}$ groove. The measured insertion loss was lower than $0.1 \mathrm{~dB}$ (98\% coupling, better than $0.5 \mu \mathrm{m}$ accuracy). The wavelength-dependent loss was less than $0.4 \mathrm{~dB}$.

\section{Acknowledgments}

This project is sponsored by the National Natural Science Foundation of China (Project Assignment No.: 50405013), the National High Technology Research and Development Program of China (863 Program, Contract No.: 2006AA04Z360), and the Foundation of the National Key Laboratory of Nano/Micro Fabrication Technology of China (Project No.: 9140C790301060C79).

\section{References}

1. Carola Strandman and Ylva B. Acklund, "Bulk silicon holding structures for mounting of optical fibers in V-grooves," J. Microelectromech. Syst 6(1), 35-40 (1997).

2. R. M. Bostock, J. D. Collier, R.-J. E. Jansen, R. Jones, D. F. Moore, and J. E. Townsend, "Silicon nitride microclips for the kinematic location of optic fibres in silicon V-shaped grooves," J. Micromech. Microeng. 8, 342-360 (1998).

3. K. E. Petersen, "Silicon as mechanical material," Proc. IEEE 70(5), 420-457 (1982). 